\title{
Avaliação da qualidade da água dos bebedouros de um campus universitário do semiárido nordestino
}

Paulo Henrique da Silva ${ }^{i}$

Ykaro Richard Oliveiraii

Otávia Caracas Câmaraiii

Maria Carolina de Abreu ${ }^{\text {iv }}$

Ana Carolina Landim Pachecov

\section{Registro DOI: http://dx.doi.org/10.22280/revintervol12ed1.418}

\begin{abstract}
Resumo
Os bebedouros são fontes potenciais de contaminação, seja de forma direta ou indireta. Deste modo, o presente estudo objetivou avaliar a qualidade da água dos bebedouros do Campus Senador Helvídio Nunes de Barros, Universidade Federal do Piauí. Para tanto, foram coletadas amostras dos 10 bebedouros da instituição nos meses de outubro/2011, março/2012 e julho/2012 e analisadas em triplicatas. Foram feitas análise parasitológica, microbiológica e físico-química; a qualidade da água foi avaliada segundo resoluções que estabelecem normas e padrões nacionais de controle da qualidade da água para consumo humano. Os bebedouros não apresentaram nenhuma forma de contaminação de estruturas parasitárias ou alteração físicoquímica, mas todos apresentaram alguma forma, ou em algum momento, contaminação microbiológica. Além disso, na última coleta realizada houve um aumento no nível de contaminação da água, provavelmente, pelo fato de ter sido realizada no período de greve dos docentes e técnicos da universidade, o que diminuiu a utilização dos bebebouros, fazendo com que a água ficasse parada no reservatório, favorecendo a proliferação de microrganismos ou devido ao final do período chuvoso, o que pode ter levado a um maior índice de contaminação dos poços de abastecimento. Assim, evidencia-se a necessidade de monitoramento da qualidade da água, manutenção dos bebedouros, bem como, promoção de medidas de Educação Sanitária para a comunidade do campus universitário.
\end{abstract}

Palavras-chave: Análise físico-química. Análise microbiológica. Picos-PI. Poluição da água.

\section{Water quality evaluation of drinking fountains of a university campus at northeastern} semi-arid

\begin{abstract}
Drinking fountain are potential sources of contamination, directly or indirectly. Thus, the present study aimed to evaluate the water quality of drinking fountains of the Senador Helvidio Nunes de Barros Campus, Federal University of Piaui. For this purpose, samples were collected from the 10 drinking fountain of the institution in the month's october/2011, march/2012 and


July/2012 and analyzed in triplicates. Parasitological, microbiological and physical-chemical analyzes were performed; water quality was evaluated according to resolutions that establish Brazilian oficial standards for water quality control for human consumption. The drinking fountains did not present any form of contamination by parasitic structures or physical-chemical alteration, but somehow or in some point, all presented microbiological contamination. In addition, in the last collect, there was an increase in the level of water contamination, probably because it was carried out in a strike period of the university's teachers and technicians, which reduced the use of drinking fountains and stored the water in the reservoir and favored the proliferation of microorganisms. Moreover, the collect occurred in the end of rainy season, which may have led to a higher contamination index of the supply wells. Thus, it is evident the need to monitor water quality and maintenance of drinking fountains, as well the promotion of Sanitary Education measures for the university campus community.

Keywords: Physical-chemical analysis. Microbiological analysis. Picos-PI. Water pollution.

\section{Recebido em 18/11/2018 Aceito em 28/01/2019}

\section{INTRODUÇÃo}

A água é o mais importante recurso natural, considerada o alimento mais consumido pela população e indispensável em todos os segmentos da vida. O maior contato do homem com a água justifica e explica a facilidade com que esta pode ser contaminada por organismos macro e microscópicos, que atingem o corpo humano e nele se desenvolvem, dependendo das condições encontradas favoráveis a sua sobrevivência (CABRAL, 2010).

Considerando a relação direta da qualidade da água com a saúde pública, o acesso à água de boa qualidade torna-se um direito vital de todos os seres humanos (SANTANA, 2011). Para tanto, as águas de abastecimento são importantes meios de veiculação de microrganismos patogênicos (HLAVSA et al., 2011), sendo que, a contaminação pode ocorrer pela descontinuidade do fornecimento, falhas no saneamento básico, manutenção inadequada de rede e reservatórios ou contaminantes diretos dos lençóis freáticos (SOARES; BERNARDES; NETTO, 2002; BETTEGA et al., 2006).

Apenas $30 \%$ da população mundial tem acesso à água tratada, os $70 \%$ restantes possuem fontes alternativas de água como poços, as quais são mais propícias à contaminação (FERNANDEZ; 
SANTOS, 2007). No Brasil, principalmente no semiárido, a água obtida de poços artesanais, rios, riachos e lagos tem sido comumente utilizada para o consumo humano, entretanto, esse tipo de fonte de água, hoje, sofre um crescente processo de degradação em função do despejo de esgotos in natura ou tratados, de fezes de animais (silvestres e de produção), além dos efluentes resultantes das atividades industriais (DOWBOR; TAGNIN, 2005).

As doenças de veiculação hídrica representam patologias gastrointestinais causadas por microrganismos patogênicos como bactérias e protozoários, assim como vírus, podendo atingir um índice de até $80 \%$ de doenças presentes em populações negligenciadas de países em desenvolvimento (GERMANO; GERMANO, 2001; COELHO et al., 2007; HLAVSA et al., 2011). No Brasil, há grande incidência dessas enfermidades, acarretadas pela carência nos serviços de saneamento, principalmente no que se refere ao esgotamento sanitário, com maior carência nas áreas periféricas dos centros urbanos e nas zonas rurais, onde se concentra a população mais pobre (JUNIOR; PAGANINI, 2009).

O Ministério da Saúde através da Portaria MS № 2914/2011 estabelece os procedimentos e responsabilidades relativos ao controle e vigilância da qualidade da água para consumo humano e seu padrão de potabilidade, determinando os Valores Máximos Permissíveis (VMP) para as características microbiológicas, organolépticas, físicas e químicas da água potável. A referida portaria determina que a água para o consumo humano deve apresentar ausência em $100 \mathrm{ml}$ de Escherichia coli e de coliformes totais e menos que $500 \mathrm{UFC} / \mathrm{ml}$ de Bactérias heterotróficas (BRASIL, 2011).

A vigilância em saúde ambiental relacionada à qualidade da água para consumo humano deve ser uma atividade rotineira preventiva de ação sobre os sistemas públicos e soluções alternativas de abastecimento, a fim de garantir o conhecimento da situação da água para consumo humano. Dessa maneira, torna-se possível minimizar os riscos na contaminação de enfermidades que possuem veiculação hídrica (BRASIL, 2004).

Os bebedouros se constituem como fontes potenciais de contaminação de forma direta através da água que é neles consumida ou, indiretamente, por meio do contato com o aparelho, uma vez que são utilizados por muitos indivíduos com hábitos de higiene desconhecidos (ARAÚJO; BARAÚNA; MENESES, 2009), sendo que o teste de água funciona como relevante no sentido de assegurar o correto funcionamento do abastecimento de água, com vistas à segurança da água potável, para investigação de surtos de doenças (BAIN et al., 2012).

Deste modo, considerando que a água é um bem essencial para sustentar a vida, e uma oferta satisfatória (adequada e segura) deve ser acessível a todos (WHO, 2011), este estudo objetivou 
avaliar a qualidade da água dos bebedouros do campus Senador Helvídio Nunes de Barros (CSHNB), Universidade Federal do Piauí (UFPI), localizado no sertão nordestino.

\section{MATERIAL E MÉTODOS}

O estudo caracterizado como observacional analítico foi realizado no campus Senador Helvídio Nunes de Barros-CSHNB, Universidade Federal do Piauí, na cidade de Picos-PI, o qual possui uma comunidade formada por aproximadamente 2969 discentes, 161 docentes e 43 servidores que consumem diariamente a água servida nos bebedouros desta instituição.

A amostragem foi composta por amostras de água de todos os bebedouros (composta por 10 unidades) distribuídos pela instituição, coletadas nos meses de outubro/2011, março/2012 e julho/2012 e analisadas em triplicatas. A escolha dos meses das coletas foi baseada na distribuição das chuvas da região. Sendo que a coleta realizada em outubro/2011 representaria a estação de estiagem (seca), março/2012 representaria a estação chuvosa, e julho/2012 o final da estação chuvosa.

Os bebedouros pesquisados apresentavam boa conservação externa em aço inox, os quais são pertencentes à marca Termisa, modelo BBDC - 412, classe climática T, de capacidade de 100 e 200 litros, com torneiras de jato e de presão, com indicação de fabricação do ano de 2010.

Tais reservatórios recebem água diretamente da rede de abastecimento público, que antes de chegar no reservatório dos mesmos, passam por um filtro externo (ACQUABIOS, Acqua 2000) que tem por função purificar a água, retendo partículas, odores, sabores indesejáveis, reduzindo cloro, mas sem eficiência bacteriológica. Ressalte-se que todos os filtros externos estavam dentro da data de validade dos elementos filtrantes indicados pelo fabricador. Segundo a equipe do bem-estar responsável pela limpeza da universidade é feita a manutenção e higienização dos bebedouros a cada seis meses.

As amostras foram coletadas em um volume mínimo de $400 \mathrm{ml}$ em frascos de vidro âmbar, com capacidade de 1 litro, previamente esterilizados em autoclave, contendo $0,5 \mathrm{ml}$ de solução a $1,8 \%$ de tiossulfato de sódio $\left(\mathrm{Na}_{2} \mathrm{~S}_{2} \mathrm{O}_{3}\right)$ para neutralizar o cloro residual da água dos bebedouros. Inicialmente, as torneiras dos bebedouros foras limpas e higienizadas com álcool etílico $70 \%$ e, após três minutos de escoamento foi realizada a coleta das amostras. Estas foram acondicionadas em recipiente térmico e encaminhadas ao laboratório de pesquisa, para imediata análise. 
A análise parasitológica das águas coletadas foi realizada no Laboratório de Patologia Celular e Molecular (LAPACEM) da UFPI/CSHNB. Para avaliar a presença de estruturas parasitárias, as amostras foram submetidas a repouso de 24 horas em cones de sedimentação e analisadas em triplicata, com adição do corante lugol, para a pesquisa de ovos ou larvas de helmintos (DE CARLI, 2001). As lâminas foram então analisadas ao microscópio óptico de campo largo utilizando as objetivas de 10X, 40X e 100X.

As análises microbiológicas e físico-químicas foram realizadas nos laboratórios da AGESPISA - Águas e Esgotos do Piauí S/A. Para contagem de bactérias heterotróficas foi realizado plaqueamento em profundidade de $1 \mathrm{ml}$ da amostra e $1 \mathrm{ml}$ das diluições $10^{-1}$ e $10^{-2}$ utilizando Ágar Padrão para Contagem (PCA) em placas de Petri devidamente esterilizadas e identificadas, em duplicata. As placas foram incubadas em estufa bacteriológica a $35^{\circ} \mathrm{C} \pm 0,5$ ${ }^{\circ} \mathrm{C}$ por $48 \pm 2$ horas. Foi realizada a leitura e verificação do número de Unidades Formadoras de Colônias - UFC - de acordo com a diluição (CLESCERI; GREENGERG; EATON, 1998; SILVA et al., 2005).

Para a identificação de coliformes totais e Escherichia coli utilizou-se a técnica de tubos invertidos, onde foram utilizados 10 tubos de ensaio contendo $10 \mathrm{ml}$ de Caldo Lauril Sulfato Triptose, suplementado com 4-metil-umbeliferil- $\beta$-D-glucuronídeo (LST-MUG), em concentração dupla, contendo tubos de Durham invertidos. Nestes foram inoculados $10 \mathrm{ml}$ da amostra e incubados em estufa bacteriológica a $35^{\circ} \mathrm{C} \pm 0,5^{\circ} \mathrm{C}$ por $48 \pm 2$ horas. Após a incubação foi verificada a presença de gás nos tubos de Durham (prova presuntiva positiva) (MARQUEZI; GALLO; DIAS, 2010).

Para análise físico-química foram analisados: amônia pelo método do fenato; cloretos pelo método de Mohr; cor pelo método colorimétrico; dureza pelo método volumétrico com ácido etilenodiamino tetra-acético (EDTA); nitrato pelo método da redução de cádmio; nitrito pelo método do N-naftil; $\mathrm{pH}$ pelo método potenciométrico e turbidez pelo método por espectrofotometria (PARRON; MUNIZ; PEREIRA, 2011).

A qualidade da água foi avaliada comparando-se os resultados obtidos nas análises parasitológicas; bacteriológicas e físico-químicas com os Valores Máximos Permissíveis recomendados na Portaria $n^{\circ} 2914$ de dezembro de 2011 - Norma de Qualidade da Água para Consumo Humano, do Ministério da Saúde; e Resolução n 357, de março de 2005 do Conselho Nacional do Meio Ambiente (CONAMA), Ministério do Desenvolvimento Urbano (MDU) e Meio Ambiente (MMA) (BRASIL, 2011; CONAMA, 2005). 


\section{RESULTADOS E DISCUSSÃo}

\section{Revinter}

Os resultados evidenciaram que as amostras de água dos 10 bebedouros analisados não apresentaram nenhuma forma de contaminação de estruturas parasitárias ou alteração físicoquímica, encontrando-se dentro do esperado pela legislação (Portaria MS N 2914/2011), como demonstrado na tabela 01 .

Tabela 1. Análise físico-química de potabilidade da água dos 10 bebedouros do CSHNB/UFPI, no período de outubro de 2011 a julho de 2012 (média das 3 coletas).

\begin{tabular}{c|c|c|c|c|c|c|c|c|c|c|c}
\hline Portaria 2914/11-MS & \multicolumn{10}{|c}{ Bebedouros } \\
\hline $\begin{array}{c}\text { Parâmetro } \\
\text { Analisado }\end{array}$ & $\mathbf{V M P}^{(\mathbf{1})}$ & $\mathbf{1}$ & $\mathbf{2}$ & $\mathbf{3}$ & $\mathbf{4}$ & $\mathbf{5}$ & $\mathbf{6}$ & $\mathbf{7}$ & $\mathbf{8}$ & $\mathbf{9}$ & $\mathbf{1 0}$ \\
\hline Cor $^{(2)}$ & 15 & 0,0 & 0,0 & 0,0 & 0,0 & 0,0 & 0,0 & 0,0 & 0,0 & 0,0 & 0,0 \\
\hline Turbidez $^{(3)}$ & 5 & 0,45 & 0,54 & 0,23 & 0,39 & 0,27 & 0,21 & 0,25 & 0,34 & 0,33 & 0,28 \\
\hline $\mathrm{pH}$ & $6-9,5$ & 7,6 & 7,7 & 7,7 & 7,7 & 7,7 & 7,7 & 7,7 & 7,9 & 7,8 & 7,7 \\
\hline Dureza total & 500 & 59 & 67 & 73 & 74 & 76 & 67 & 76 & 65 & 70 & 71 \\
\hline Nitrato & 10 & 0,0 & 0,0 & 0,0 & 0,0 & 0,0 & 0,0 & 0,0 & 0,0 & 0,0 & 0,0 \\
\hline Nitrito & 1 & 0,0 & 0,0 & 0,0 & 0,0 & 0,0 & 0,0 & 0,0 & 0,0 & 0,0 & 0,0 \\
\hline Amônia & 1,5 & 0,0 & 0,0 & 0,0 & 0,0 & 0,0 & 0,0 & 0,0 & 0,0 & 0,0 & 0,0 \\
\hline Cloreto & 250 & 16 & 13 & 14,0 & 14,0 & 11,0 & 10,0 & 13 & 16 & 14,0 & 12,0 \\
\hline
\end{tabular}

Legenda: ${ }^{(1)}$ VMP- Valor Máximo Permitido, ${ }^{(2)}$ Unidade Hazen $(\mathrm{mgPt}-\mathrm{Co} / \mathrm{L}),{ }^{(3)}$ Unidade de turbidez.

Fonte: Os Autores.

Por sua vez, Mendes et al. (2016) avaliando a qualidade físico-químico da água dos bebedouros de cinco campus da Universidade do Estado do Pará, na cidade de Belém, bebedouros de três dos campus apresentaram-se impróprias ao consumo humano, devido amostras com valores irregulares de $\mathrm{pH}$ e do fósforo de acordo com a legislação vigente.

Entretanto, no presente estudo $100 \%$ das unidades de bebedouros apresentaram contaminação microbiológica em pelo menos uma das coletas realizadas, conforme está demonstrado na tabela 2 e no gráfico 1, estando fora dos padrões exigidos pela legislação brasileira, a qual diz que a água para o consumo humano deve apresentar ausência em $100 \mathrm{~mL}$ de E. coli e de coliformes totais e menos que $500 \mathrm{UFC} / \mathrm{ml}$ de Bactérias heterotróficas.

Tabela 2. Análise microbiológica para determinação de Coliformes totais e Escherichia coli dos 10 bebedouros do CSHNB/UFPI no período de outubro de 2011 a julho de 2012.

\begin{tabular}{c|c|c|c|c|c|c}
\hline \multirow{2}{*}{ Bebedouro } & \multicolumn{3}{|c|}{ Coliformes totais } & \multicolumn{3}{c}{ Escherichia coli } \\
\cline { 2 - 7 } & $\begin{array}{c}\text { Coleta } \\
\mathbf{1}\end{array}$ & Coleta 2 & Coleta 3 & Coleta 1 & $\begin{array}{c}\text { Coleta } \\
\mathbf{2}\end{array}$ & $\begin{array}{c}\text { Coleta } \\
\mathbf{3}\end{array}$ \\
\hline $\mathbf{1}$ & - & - & + & - & - & + \\
\hline $\mathbf{2}$ & - & - & + & - & - & + \\
\hline $\mathbf{3}$ & - & + & - & - & - & - \\
\hline
\end{tabular}

Revinter, v. 12, n. 01, p. 27-39, fev. 2019. 


\begin{tabular}{c|c|c|c|c|c|c}
\hline $\mathbf{4}$ & - & - & + & - & - & + \\
\hline $\mathbf{5}$ & + & - & - & - & - & - \\
\hline $\mathbf{6}$ & - & + & - & - & - & - \\
\hline $\mathbf{7}$ & - & - & + & - & - & + \\
\hline $\mathbf{8}$ & - & - & + & - & - & + \\
\hline $\mathbf{1 0}$ & - & - & + & - & - & + \\
\hline
\end{tabular}

Legenda: + presença; - ausência.

Fonte: Os Autores.

Gráfico 1. Contagem de bactérias heterotróficas dos 10 bebedouros da UFPI/CSHNB no período de outubro de 2011 a julho de 2012.

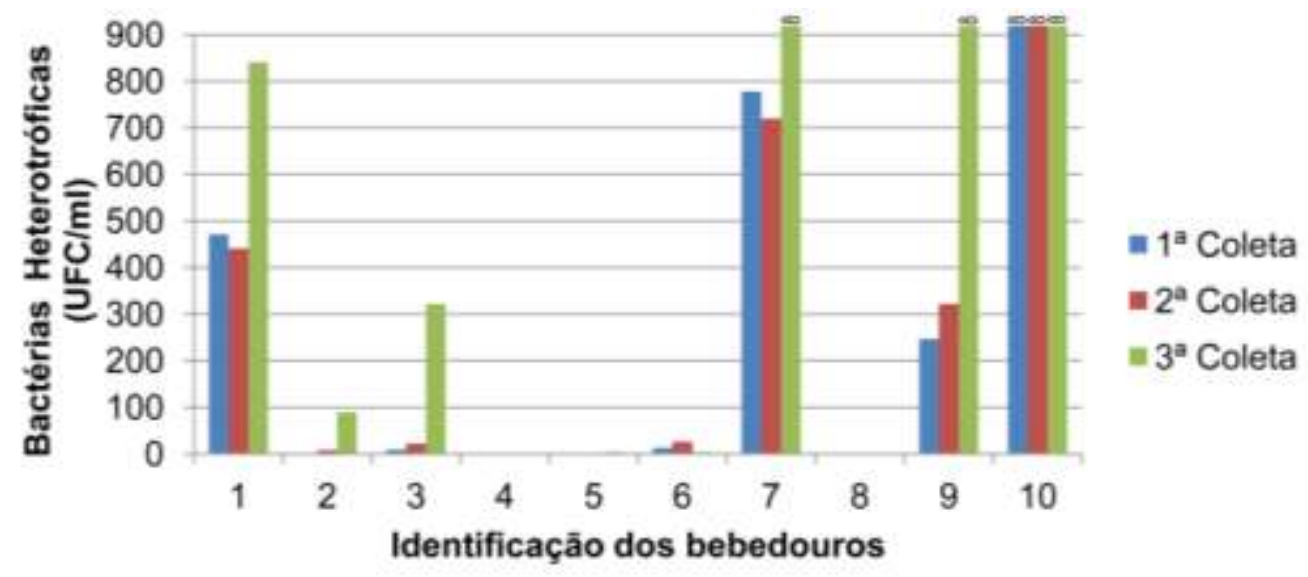

Fonte: Os Autores.

Ressalte-se que esta ocorrência, em fontes de água tratada, é a mais comum causa de violação dos padrões de potabilidade. Tradicionalmente, a presença de bactérias termotolerantes em água potável tem sido vista como um indicador de contaminação fecal intimamente ligada ao tratamento inadequado ou inabilidade em manter desinfecção residual em água tratada em caixas e reservatórios (AZEREDO et al., 2001; SILVA et al., 2010).

Observou-se ainda que, nas amostras da última coleta realizada, houve um aumento significativo da contaminação microbiológica dos bebedouros analisados, onde acredita-se que este aumento pode estar relacionado a dois fatos: a) diminuição da comunidade acadêmica durante o período da greve de técnicos e docentes desta instituição, ocasionando uma diminuição do consumo da água dos bebedouros com consequente proliferação de microrganismos devido a água parada ou b) devido ao período de finalizacão da estação chuvosa, período que pode levar a um maior índice de contaminação da água de poços, como 
descrito por Camargo e Paulosso (2009), utilizados pela Companhia de Abasteciamento de Água do Piauí.

Os bebedouros que apresentaram maior contaminação para bactérias heterotróficas $(1,7,9$ e 10) foram dois localizados no bloco do restaurante universitário e dois em um bloco de sala de aula, sendo um localizado próximo ao banheiro e o outro que apresentava um problema no fechamento da tampa superior do bebedouro.

Os resultados encontrados nesta pesquisa, apesar de apresentar um nível maior de contaminação microbiológica (100\% das amostras estavam contaminadas), corroboram com vários resultados de contaminação de água distribuída para consumo humano realizado em várias regiões do país. Em uma pesquisa realizada por Trindade et al. (2015) em três escolas escolas públicas na cidade de Macapá-AP, a água nestas instituições não atenderam aos requisitos de potabilidade preconizados pelo Ministério da Saúde através da Portaria no 2914/11, requerendo ações urgentes na adequação da água ofertada às comunidades escolares, a fim de evitar danos a saúde de seus usuários.

Em outro estudo, realizado por Siqueira et al. (2010), dentre as amostras de água de 40 estabelecimentos de alimentos localizados no entorno da Universidade Federal Rural de Pernambuco (UFRPE) e da Universidade Federal de Pernambuco (UFPE), 62,5\% apresentaram coliformes totais e 42,5\% apresentaram coliformes termotolerantes. Ainda no estado de Pernambuco, um estudo sobre qualidade da água em solução alternativa de abastecimento em Cabo de Santo Agostinho, verificou contaminação por E. coli em 65,38\% das amostras (OLIVEIRA, 2011).

Nascimento et al. (2013) analisaram amostras de água em escolas estaduais do município Campo Mourão (PR) e evidenciaram em 33,33\% contaminação com coliformes totais, e em $6,66 \%$ contaminação por $E$. coli, sugerindo contaminação fecal. Carvalho et al. (2009) analisando amostras de 21 bebedouros, no município de Ipatinga-MG, encontraram resultados relacionados à contagem de bactérias heterotróficas que demonstraram que todas as amostras apresentaram valores superiores aos valores permitidos, caracterizando a contaminação água, tornando-a assim imprópria para o consumo humano, no município de.

No entanto, alguns estudos apontam a ausência de contaminação da água oferecida para consumo humano, demonstrando a boa qualidade do produto. Em pesquisa realizada no estado do Paraná, onde foram avaliados 19 amostras de água de bebedouros da Universidade Estadual de Londrina - UEL, nenhuma amostra apresentou algum tipo de contaminação, obedecendo 
aos padrões de qualidade exigidos pela portaria $n^{0} 2914$ do Ministério da Saúde, sendo, portanto, águas apropriadas para o consumo (SECO; BURGOS; PELAYO, 2012).

Analisando águas e superfícies de bebedouros de parques de Curitiba, Reis et al. (2012) constatou que a contagem de coliformes totais e termotolerantes demonstrou padrão de qualidade satisfatório; a contagem de bactérias heterotróficas demonstrou crescimento abaixo do valor de referência estabelecido.

Barbosa, Lage e Badaró (2009) descreveram que apesar de algumas das 20 amostras de água de bebedouros que foram analisadas de Campus Universitário do município de Ipatinga-MG, apresentarem uma alta contagem de bactérias heterotróficas, nenhuma apresentou coliformes totais e E. Coli, classificando a água como de boa qualidade. Dantas et al. (2010) também verificaram ausência de coliformes totais ou fecais em amostras de água de 14 bebedouros de dois campus da Universidade Federal dos Vales do Jequitinhonha e Mucuri - UFVJM, porém, foram encontrados fungos em algumas amostras.

Desse modo, pesquisas acerca da avaliação da qualidade de água de bebedouros realizadas no Brasil apresentam uma discrepância entre os resultados apresentados, indicando que a contaminação pode ser devido à origem da água distribuída, aos métodos de conservação e armazenamento da água e sua posterior distribuição e manutenção das boas condições dos reservatórios de água, bem como, da manutenção dos bebedouros.

\section{CONSIDERAÇÕES FINAIS}

Frente aos resultados descritos, pode-se evidenciar que os bebedouros utilizados da Universidade Federal do Piauí, Campus Senador Helvídio Nunes de Barros, Picos-PI, estão fora do preconizado pela legislação, sugerindo que o sistema de higienização adotado pelo centro acadêmico apresenta baixa eficácia em manter a qualidade da água, portanto, seu consumo pode representar um risco à saúde pública.

Dessa maneira, se faz necessário um monitoramento da qualidade da água, a manutenção constante dos bebedouros e de medidas que promovam a Educação Sanitária da comunidade do campus através de ações que orientem e conscientizem quanto aos hábitos higiênicos adequados na utilização dos bebedouros, que muitas vezes são utilizados de maneira inadequada, podendo assim garantir uma água de qualidade a todos que utilizarem os bebedouros deste campus universitário. 


\section{REFERÊNCIAS BIBLIOGRÁFICAS}

ARAÚJO, T. M., BARAÚNA, A. C., MENESES, C. A. R. Identificação de Escherichia coli em água de bebedouros e nos próprios aparelhos de quatro escolas públicas de Boa Vista Roraima - Brasil. In: Congresso de Pesquisa e Inovação da Rede Norte Nordeste de Educação Tecnológica (CONNEP), 2009, Belém. Anais... Belém, 2009.

AZEREDO, G.A., MOURA, M.A., CONCEIÇÃO, M.L., SILVA, J.A. Caracterização das águas dos bebedouros do Campus I - UFPB, sob o ponto de vista microbiológico. Revista Higiene Alimentar, v. 15, n. 90/91, p. 79-82, 2001.

BAIN, R., BARTRAM, J., ELLIOTT, M., MATTHEWS, R., MCMAHAN, L., TUNG, T., CHUANG, P., GUNDRY, S. A Summary Catalogue of Microbial Drinking Water Tests forLow and Medium Resource Settings. International Journal of Environmental Research and Public Health, v. 7, n. 5, p. 1609-1625, 2012.

BARBOSA, D. A., LAGE, M. M., BADARÓ, A. C. L. Qualidade microbiológica da água dos bebedouros de um campus universitário de Ipatinga, Minas Gerais. Revista Digital de Nutrição, v. 3, n. 5, p. 505-517, 2009.

BETTEGA, J. M. R., MACHADO, M. R., PRESIBELLA, M., BANISKI, G., BARBOSA, C. A. Métodos analíticos no controle microbiológico da água para consumo humano. Revista Ciência Agrotécnica, v. 30, n. 5, p. 950-954, 2006.

BRASIL. Ministério da saúde. Secretaria de vigilância em saúde. Programa nacional de vigilância em saúde ambiental relacionada à qualidade da água para consumo humano. Brasília: Editora do Ministério da Saúde, 2004. 106 p.

BRASIL. Portaria MS n. ${ }^{\circ}$ 2914/2011, Dispõe sobre os procedimentos de controle e de vigilância da qualidade da água para consumo humano e seu padrão de potabilidade.

Disponível em:

<www.suvisa.rn.gov.br/contentproducao/aplicacao/sesap_suvisa/arquivos/gerados/portaria_m s_2914_dez_2011.pdf>. Acesso em: 24 mai. 2013.

CABRAL, J. P. S. Water microbiology: bacterial pathogens and water. International Journal of Environmental Research and Public Health, v. 7, n. 10, p. 3657-3703, 2010.

CAMARGO, M. F., PAULOSSO, L. V. Avaliação qualitativa da contaminação microbiológica das águas de poços no município de Carlinda - MT. Semina: Ciências Biológicas e da Saúde, v. 30, n. 1, p. 77-82, 2009.

CARVAlHO, D. R., FORTUNATO, J. N., VIlELA, A. F., BADARÓ, A. C. L. Avaliação da qualidade físico-química e microbiológica da água de um campus universitário de Ipatinga - MG. Revista Digital de Nutrição, v. 3, n. 5, p. 417-427, 2009.

CLESCERI, L. S., GREENGERG, A. E., EATON, A. D. Standard methods of the examination of water and wastewater. 20ty ed., Washington: American Public Health Association (APHA), American Water Works Association (AWWA), Water Environmental Federation (WEF), 1998. 1325p. 


\section{Revinter}

COELHO, D. A., SILVA, P. M. F., VEIGA, S. M. O. M., FIORINI, J. E. Avaliação da qualidade microbiológica de águas minerais comercializadas em supermercados da cidade de Alfenas, MG. Revista Higiene Alimentar, v. 21, n. 151, p. 88-92, 2007.

CONAMA. Ministério do Meio Ambiente, Conselho Nacional do Meio Ambiente. Resolução CONAMA N 357/2005. Dispõe sobre a classificação dos corpos de água e diretrizes ambientais para o seu enquadramento, bem como estabelece as condições e padrões de lançamento de efluentes, e dá outras providências. Disponível em: <http://www.mma.gov.br/port/conama/res/res05/res35705.pdf>. Acesso em: 15 jul. 2013.

DANTAS, A. K. D., SOUZA. C., FERREIRA, M. S., ANRADE, M. A., ANDRADE, D., WATANABE, E. Qualidade microbiológica da água de bebedouros destinada ao consumo humano. Revista Biociências, v. 16, n.2, p. 132-138, 2010.

DE CARLI, G. A. Parasitologia Clínica: seleção de métodos e técnicas de laboratório para o diagnóstico de parasitoses humanas. São Paulo: Editora Atheneu, 2001. 810p.

DOWBOR, L., TAGNIN, A. Administrando a água como se fosse importante: gestão ambiental e sustentabilidade. São Paulo: Editora Senac, 2005. 299p.

FERNANDEZ, A.T., SANTOS, V. C. Avaliação de parâmetros físico-químicos e microbiológicos da água de abastecimento escolar, no município de Silva Jardim, RJ. Revista Higiene Alimentar, v. 21, n. 154, p. 93-98, 2007.

GERMANO, P. M. L., GERMANO, M. I. S. Higiene e vigilância sanitária de alimentos. $2^{\text {a }}$ ed. São Paulo: Livraria Varela, 2001. 629p.

HLAVSA, M. C., ROBERTS, V. A., ANDERSON, A. R., HILL, V. R., KAHLER, A. M., ORR, M., GARRISON, L. E., HICKS, L. A., NEWTON, A., HILBORN, E. D., WADE, T. J., BEACH, M. J., YODER. J. S. Centers for disease control and prevention: surveillance for waterborne disease outbreaks and other health events associated with recreational water United States, 2007- 2008. Morbidity Mortality Weekly Report, v. 60, n. 12, p. 1-32, 2011.

JUNIOR, A. C. G., PAGANINI, W. S. Aspectos conceituais da regulação dos serviços de água e esgoto no Brasil. Engenharia Sanitária e Ambiental, v. 14, n. 1, p. 78-88, 2009.

MARQUEZI, M. C.; GALLO, C. R.; DIAS, C. T. S. Comparação de métodos para análise de coliformes totais e E. coli em amostras de água. Revista do Instituto Adolfo Lutz , v. 69, n. 3, p. 291-296, 2010.

MENDES, M. P, SILVA, N.S.G., CARVALHO, J.R.C., JUNIOR, J.B.P., DINIZ, V.W.B. Avaliação da qualidade da água dos bebedouros da Universidade do Estado do Pará na cidade de Belém Pará, Brasil. Scientia Plena, v. 12, n. 6, p. 1-7, 2016.

NASCIMENTO, D. C., RIBAS- SILVA, R. C., PAVANELLI, M. F. Pesquisa de coliformes em água consumida em bebedouros de escolas estaduais de Campo Mourão, Paraná. Revista Saúde e Biologia, v. 8, n. 1, p. 21-26, 2013. 
OLIVEIRA, K. A. Qualidade da água para consumo humano em solução alternativa de abastecimento no município do Cabo de Santo Agostinho, Pernambuco. 16 f. 2011. Trabalho de Conclusão de Curso (Especialização em Saúde Pública) - Departamento de Saúde Coletiva, Centro de Pesquisas Aggeu Magalhães, Fundação Oswaldo Cruz, Recife, 2011.

PARRON, L. M.; MUNIZ, D. H. F.; PEREIRA, C. M. Manual de procedimentos de amostragem e análise físico-química de água. Colombo: Embrapa Florestas, 2011. 67 p.

REIS, F., DIAS, C. R., ABRAHÃO, W. M., MURAKAMI, F. S. Avaliação da qualidade microbiológica de águas e superfícies de bebedouros de parques de Curitiba - PR. Visão Acadêmica, v. 13, n. 1, p. 55-70, 2012.

SANTANA, J. A. S. Qualidade da água das escolas municipais de Igarassu - PE. $22 \mathrm{f}$. 2011. Plano de Intervenção (Especialização em Gestão de Sistemas e Serviços em Saúde) Centro de Pesquisas Aggeu Magalhães, Fundação Oswaldo Cruz, Recife, 2011.

SECO, B. M. S., BURGOS, T. N., PELAYO, J. S. Avaliação bacteriológica das águas de bebedouros do campus da Universidade Estadual de Londrina - PR. Semina: Ciências Biológicas e da Saúde, v. 33, n. 2, p. 193-200, 2012.

SILVA, N., JUNQUEIRA, V., SILVEIRA, N. F. A., TANIWAKI, M. H., SANTOS, R. F. S., GOMES, R. A. R. Manual de métodos de análise microbiológica de alimentos e água. 4th ed. São Paulo: Livraria Varela, 2010. 614p.

SILVA, N., NETO, R. C., JUNQUEIRA, V. C. A., SILVEIRA, N. F. Manual de métodos de análise microbiológica de água. São Paulo: Livraria Varela, 2005. 165p.

SIQUEIRA, L. P., SHINOHARA, N. K. S., LIMA, R. M. T., PAIVA, J. E., FILHO, J. L. L., CARVALHO, I. T. Avaliação microbiológica da água de consumo empregada em unidades de alimentação. Ciência \& Saúde Coletiva, v. 15, n. 1, p. 63-66, 2010.

SOARES, S. R. A., BERNARDES, R. S., NETTO, O. M. C. 2002. Relações entre saneamento, saúde pública e meio ambiente: elementos para formulação de um modelo de planejamento em saneamento. Revista Caderno de Saúde Pública, v. 18, n. 6, p. 1713-1724, 2002.

TRINDADE, G. A., SÁ-OLIVEIRA, J. C., SILVA, E. S. Avaliação da qualidade da água em três Escolas Públicas da Cidade de Macapá, Amapá. Biota Amazônia, v. 5, n. 1, p. 116-122, 2015.

WORLD HEALTH ORGANIZATION. Guidelines for drinking water quality. Engenharia Sanitaria e Ambiental, v. 16, n. 4, 2011.

\footnotetext{
' Unidade Acadêmica de Ciências Biológicas, Universidade Federal do Piauí-UFPI, Campus Universitário Senador Helvídio Nunes de Barros. Rua Cícero Duarte, 905 - Bairro Junco, Picos, Piauí, Brasil.
} 


\section{Revinter}

ii Unidade de Pós-Graduação em Botânica (Mestrado), Departamento de Ciências Biológicas, Universidade Estadual de Feira de Santana-UEFS. Avenida Transnordestina, s/n, Novo Horizonte, Feira de Santana, Bahia, Brasil.

iii Docente do Departamento de Ciências Biológicas, Universidade Estadual do Piauí, Campus Universitário Barros Araújo, BR 316, bairro Altamira, Picos, Piauí, Brasil.

iv Docente do Departamento de Ciências Biológicas, Universidade Federal do Piauí, Campus Universitário Senador Helvídio Nunes de Barros. Rua Cícero Eduardo, 905 - Bairro Junco, Picos, Piauí, Brasil.

$\checkmark$ Docente do Departamento de Ciências Biológicas, Universidade Federal do Piauí, Campus Universitário Senador Helvídio Nunes de Barros. Rua Cícero Eduardo, 905 - Bairro Junco, Picos, Piauí, Brasil. E-mail para contato: carolandim@ufpi.br 